\title{
Improving growth indices and productivity of phytochemical compounds in lemon balm (Melissa officinalis L.) through induced polyploidy
}

\author{
Daryush Talei ${ }^{1 *}$, Mohammad Hossein FotoKian ${ }^{2}$ \\ ${ }^{1}$ Medicinal Plants Research Center, Shahed University, Tehran, Iran \\ ${ }^{2}$ Faculty of Agriculture, Shahed University, Tehran, Iran
}

\begin{abstract}
The induction of polyploidy using mutagenic chemicals is one of the plant breeding methods to enhance the production of secondary metabolites. In the current research, to induce polyploidy in lemon balm (Melissa officinalis) plants, seeds were treated with different concentrations of colchicine for various exposure times. A factorial experiment was performed using a randomized complete block design with two factors: colchicine concentrations with four levels (control, $0.05 \%, 0.1 \%$, and $0.2 \%$ ) and exposure times with three levels $(24,48$, and $72 \mathrm{~h}$ ) and three replicates. The physiological and phytochemical traits of plants were measured at a $4-6$ leave stage. The results indicated that different concentrations of colchicine had a significant effect on the chlorophyll a (Chl.a), chlorophyll b (Chl.b), carotenoid, phenol, flavonoid, and rosmarinic acid contents. The exposure times of colchicine also caused significant changes in Chl.a, Chl.b, carotenoid, phenol, flavonoid, and rosmarinic acid amounts $(P \leq 0.01)$. Increasing the colchicine concentration significantly increased the physiological and phytochemical traits at $0.05 \%$ and $0.1 \%$ concentration in comparison to the control $(P \leq 0.01)$. In contrast, the interaction of colchicine concentration and exposure time had a significant effect on Chl.a, Chl.b, carotenoid, and rosmarinic acid amounts. The findings of this study indicate that one of the effective methods in primary screening of polyploidy plants in the polyploidization breeding program is the estimation of the physiological changes, the contents of chlorophyll $\mathrm{a}$ and $\mathrm{b}$, and the total amount of chlorophyll and secondary metabolites. Flow cytometry is recommended to be used for the accurate identification of the ploidy level in M. officinalis.
\end{abstract}

Key words: colchicine, flavonoid, lemon balm, physiological traits, rosmarinic acid

\section{Introduction}

Lemon balm (Melissa officinalis L.) is an aromatic plant of the Lamiaceae family, with the chromosome number of 32 and 64 (Kittler et al., 2015). The plant is grown worldwide, but its origin is not well defined, although the Mediterranean region or western Asia is considered to be its area of origin. The leaves of the plant contain three major phytochemical compounds, namely protocatechuic acid, caffeic acid, and rosmarinic acid (Soltani Maivan et al., 2017). The herb exhibits a broad range of pharmaceutical properties such as sedative, carminative, antispasmodic, antibacterial, antiviral, antifungal, anti-in ammatory, and antioxidative; furthermore, M. officinalis is used to treat Graves', Alzheimer's, and thyroid diseases (Bagdat and Cosge, 2012; Kim et al., 2010; Weitzel and Petersen, 2011).

The production of polyploid plants has been one of the objectives of the breeding programs for obtaining differentiated genotypes to maximize traits of agronomic interest. Polyploid plants may occur naturally, arising from some cytological mechanisms such as the formation of unreduced gametes, but they may also be obtained synthetically by the induction of chromosome duplication of somatic cells. This procedure is possible by using antimitotic substances or thermal shocks to interfere with the cell cycle. It affects the organization/polymerization or causes the segregation of microtubules, which inhibits the separation of chromosomes

\footnotetext{
* Corresponding author: Medicinal Plants Research Center, Shahed University, Tehran 3319118651, Iran; e-mail: d.talei1348@gmail.com
} 
and leads to the formation of cells with a duplicated chromosome complement (Dhooghe et al., 2011).

Colchicine $\left(\mathrm{C}_{22} \mathrm{H}_{25} \mathrm{O}_{6} \mathrm{~N}\right)$ is a hormonal plant product extracted from the seeds and bulbs of Colchicum autumnale L. It is an antimitotic agent used to induce the formation of polyploids (Dhooghe et al., 2011; Stanys et al., 2004). Colchicine binds specifically to the tubulin dimmers to prevent the formation of microtubules to induce polyploidization (Otto, 2007; Petersen et al., 2003). Several studies have reported successful artificial polyploidy induction in various plant species and families (Dhooghe et al., 2011; Ojiewo et al., 2007; Otto, 2007). These artificial polyploidial effects caused by colchicine may induce morphological, cytological, histological, and even genetic changes (Manzoor et al., 2019; Munzbergova, 2017). The use of colchicine can increase the number of chromosomes and ultimately increase the amount of metabolites in the treated plant.

Castro et al. (2003) treated Lolium multiflorum seeds with $0.2 \%$ and $0.4 \%$ colchicine solutions and observed considerable effects on certain agronomic traits such as leaf size, changes in the allele frequency, and pronounced mutagenic effects in the plants. Polyploidization in basic chromosome numbers is a major source of evolution and quality production of flowering plants (Zlesak et al., 2005). Amiri et al. (2010) reported that polyploidy in ornamental plants caused enlargement in the size of flowers and leaves, a sturdier stem, intensification of colors, harder and more robust plants, thicker and more rigid foliage, apparent increase in tolerance to different stresses, resistance to diseases and insects, and reduction in the fertility of flowering plants.

Dhawan and Lavania (1996) reported that artificial polyploidy generally enhances the vigor of plant parts under study and may be favorable where vegetative organs and biomass constitute an economical product. Alam et al. (2011) reported that applying colchicine on the sprouting bud of potato led to improvement in yield potential, plant height, number of leaves, and fresh weight. Under in vitro conditions, colchicine has been successfully applied to induce polyploidy in several plants such as rhododendron (Vainola, 2000), alocasia (Thao et al., 2003), scoparia (Escandon et al., 2005), and astragalus (Chen and Gao, 2007). Dhamayanthi and Gotmare (2010) reported that colchicine is more effective in seed treatment than in seedling and steam cutting treatments in cotton. Moreover, Mishra et al. (2010) reported that polyploid plants of opium poppy (Papaver somniferum L.) showed high drought tolerance, pest resistance, and better performance, while Alam and Razaq (2015) reported that polyploid plants of tea ( $\mathrm{Ca}$ mellia sinensis L.) showed a high ability to survive in adverse environmental conditions.

A wide spectrum of secondary metabolites, resulting in an expanding growth area, and investigations for improved new varieties for better winter hardiness, higher content of essential oil, and higher yield of $M$. officinalis are of special interest in plant breeding programs. However, little information is available regarding the response of $M$. officinalis to polyploidy induced by colchicine. The present study aimed to investigate the effect of colchicine on polyploidy induction and morpho-physiological responses of lemon balm to different concentrations and exposure times of colchicine.

\section{Materials and methods}

\section{Plant material}

Lemon balm seeds were obtained from the Medicinal Plants Research Center, Shahed University, Tehran, Iran.

\section{Experimental design}

The seeds were decontaminated by dipping in $0.1 \%$ mercuric chloride solution supplemented with a few drops of Tween 20 and agitated for 5-7 min. The seeds were then thoroughly rinsed three times in sterile distilled water for $3 \mathrm{~min}$ each. The decontaminated seeds were aseptically cultured on $50 \mathrm{ml}$ Murashige and Skoog (MS) solid medium in flasks (Murashige and Skoog, 1962). The $\mathrm{pH}$ of the media was adjusted to 5.8 with $\mathrm{NaOH}$ or $\mathrm{HCl}$ before autoclaving at $120^{\circ} \mathrm{C}$ for $20 \mathrm{~min}$. The cultures were maintained in dark at $25 \pm 2^{\circ} \mathrm{C}$ until germination occurred. Once germinated, the seedlings were removed and placed in a growth room with a light regime of $16 / 8 \mathrm{~h}$ light/dark photoperiod $\left(30 \mu \mathrm{mol} \cdot \mathrm{m}^{-2} \mathrm{~s}^{-1}\right)$ provided by a mixture of cool white fluorescent tubes and incandescent lights and maintained at $25 \pm 2{ }^{\circ} \mathrm{C}$.

The in vitro germinated seedlings were used as the source of explants for subsequent experiments. The shoot explants were obtained from 4 -week in vitro germinated seedlings. The explants were surface sterilized with $10 \%$ Clorox (commercial bleach) for $10 \mathrm{~min}$ and rinsed 3 times with sterile distilled water. Next, $1 \mathrm{~cm}$ long explants were treated with different concentrations of colchicine $(0,0.05,0.1$, and $0.2 \%)$ for various expo- 
sure times (24, 48, and $72 \mathrm{~h})$. After 4 weeks of the adjustment process, the seedlings were placed in a greenhouse. Before the flowering stage, all the plants were harvested, and data on the morpho-physiological traits such as total dry weight; chlorophyll a, chlorophyll b, carotenoid, phenol, flavonoid, and rosmarinic acid contents; and chromosomal responses were measured. Different polyploidy plants were obtained, and their ploidy levels were confirmed by flow cytometry (Chavan et al., 2014).

\section{Determination of pigment contents}

The contents of chlorophyll a, chlorophyll b, total chlorophyll, and carotenoid were measured using the Lichtenthaler method (1987). Fresh leaves $(0.03 \mathrm{~g})$ were homogenized with $10 \mathrm{ml}$ of $80 \%$ chilled acetone. The extract was centrifuged at $2000 \times g$ for $10 \mathrm{~min}$. The absorbance of the supernatant was estimated spectrophotometrically at 663,645 , and $480 \mathrm{~nm}$ using a Shimadzu UV-Vis 1201 spectrophotometer. The contents of the pigments were expressed in terms of $\mathrm{mg} / \mathrm{g}$ fresh weight of tissue.

\section{Determination of the total phenolic content}

The total phenolic content was determined using the method of Marinova et al. (2005). One milliliter of the extract was diluted with $9 \mathrm{ml}$ distilled water, followed by the addition of $1 \mathrm{ml}$ of Folin-Ciocalteu's phenol reagent, and the solution was thoroughly mixed. After $5 \mathrm{~min}$, $10 \mathrm{ml}$ of $7 \% \mathrm{Na}_{2} \mathrm{CO}_{3}$ was added, and the mixture was diluted to $25 \mathrm{ml}$ by adding $4 \mathrm{ml}$ of distilled water and incubated at room temperature for $90 \mathrm{~min}$. The absorbance was measured using a spectrophotometer at $750 \mathrm{~nm}$.

\section{Determination of the total flavonoid content}

The total flavonoid content was determined using the aluminum chloride colorimetric method (Marinova et al., 2005). First, $1 \mathrm{ml}$ of extract was added to $4 \mathrm{ml}$ distilled water in a flask, followed by the addition of $0.3 \mathrm{ml}$ of $5 \%$ $\mathrm{NaNO}_{2}$. After $5 \mathrm{~min}, 0.3 \mathrm{ml}$ of $10 \% \mathrm{AlCl}_{3}$ was added, and the mixture was diluted to $10 \mathrm{ml}$ by adding $2.4 \mathrm{ml}$ distilled water. The absorbance of the mixture was measured at $510 \mathrm{~nm}$.

\section{Determination of the rosmarinic acid content}

The aerial parts of the plants were dried at $63^{\circ} \mathrm{C}$ for $48 \mathrm{~h}$. To determine the rosmarinic acid content, the dried plant material was ground into fine powder, and then, $0.5 \mathrm{~g}$ of the powder was dissolved in $30 \mathrm{ml}$ methanol and kept at room temperature for $8 \mathrm{~h}$. The process was repeated several times with the same solvent system until the solvent portion became colorless. A Whatman No. 1 filter paper was used for filtering the solvent extract. The solvent extract was then concentrated under reduced pressure by using a rotary evaporator. The concentrated extract was transferred to conical flasks, and the remaining solvent was removed. Final drying was performed by placing the concentrated extracts in an electric oven at room temperature, and the weights of the final dried extracts were measured. Four milligrams of crude extract were dissolved in HPLCgrade ethanol (Merck, Germany) to form $1 \mathrm{mg} / \mathrm{ml}$ stock solution. Twenty microliters of each working standard solution was injected into the HPLC system in five replicates. A calibration curve was generated by linear regression based on peak areas (Ozturk et al., 2010). One milliliter of each sample was finally filtered into HPLC vials by using disposable polypropylene syringe filters with $0.2 \mu \mathrm{m}$ pore size and was then subjected to HPLC analysis. The HPLC system used was an Agilent (7890A model, USA) with a C18 Eurospher100 column (125 $\times 4 \mathrm{~mm}$ and $5 \mu \mathrm{m}$ particle size).

\section{Standard preparation}

The standard compound of rosmarinic acid (99\%) was used as the reference compound. From the stock solution, serial dilutions $(0,10,20,30,40,50,60$, and $70 \mu \mathrm{g} / \mathrm{ml}$ ) were prepared and injected into the injection port of the HPLC unit. The run time was set for $3.7 \mathrm{~min}$. The retention time and the standard area were obtained. A calibration curve was generated by linear regression based on peak areas (Vijaykumar et al., 2007).

\section{Injection of the sample solution}

The extracted leaf samples were filtered and injected ( $20 \mu \mathrm{l})$ into the HPLC port with a $25 \mu \mathrm{l}$ syringe in three replicates. The run time was adjusted for $12 \mathrm{~min}$. Rosmarinic acid peaks were identified using the standard retention time and the area of the peak was recorded.

\section{Estimation of the size and density of stomata}

Fifty stomata were measured on the lower epidermis of leaves taken randomly from untreated and colchicinetreated plants. For this purpose, four well-expanded fresh leaves of control and colchicine-treated plants were 
taken, and xylene was applied to the lower epidermis and kept for drying. After drying, the lower epidermis was peeled off with forceps and was stained with trypan blue (Sigma, USA) for visualization of stomatal density under a light microscope (Olympus BX40, Shinjuku, Tokyo, Japan) at 40 and $100 \times$ magnification (Hamill et al., 1992). The difference in the stomata length between the colchicine-treated plants and control plants was observed by Cryo SEM analysis.

\section{Determination of the ploidy of the plants by flow cytometry}

Fresh leaves were collected from the control plant and plants treated with different concentrations of colchicine. The nuclei were extracted and analyzed for polyploidy by flow cytometry (CyFlow ${ }^{\circledR}$ Cube8, Partec, Germany). The leaves were chopped with a razor blade, homogenized in Petri dishes containing $400 \mathrm{ml}$ of a nuclei extraction buffer, and filtered using a $30 \mathrm{~nm}$ filter. The filtered nuclei samples were stained for $1 \mathrm{~min}$ using $1600 \mathrm{ml}$ 4',6-diamidino-2-phenylindole (DAPI) staining buffer (Yokoya et al., 2000). All extraction processes were performed on ice. The fluorescence emission was measured using a $365 \mathrm{~nm}$ filter.

To confirm the flow cytometry results, root tips were excised and pretreated with $0.002 \mathrm{M}$ 8-hydroxyquinoline for $4 \mathrm{~h}$ at room temperature, and then washed in distilled water for $5 \mathrm{~min}$. The root tips were fixed with Carnoy solution at room temperature for $24 \mathrm{~h}$. They were rinsed with distilled water and stored in $70 \%$ ethanol at $4{ }^{\circ} \mathrm{C}$ for further cytological analysis. The roots were hydrolyzed in $1 \mathrm{~N} \mathrm{HCl}$ for $12 \mathrm{~min}$ at $60^{\circ} \mathrm{C}$ and then squashed on slides containing a drop of $1 \%$ acetocarmine staining solution (Sakhanokho et al., 2009).

\section{Statistical analysis}

The experimental design was a factorial experiment based on a completely randomized two-factor design with three replicates. The obtained data were analyzed using SPSS version 25 , and mean comparisons were made following Duncan's multiple range test at $P \leq 0.05$.

\section{Results}

\section{Effect of colchicine concentrations and exposure times on total dry weight}

The analysis of variance revealed that colchicine concentrations (C) and exposure times (T) significantly affected the total shoot and root dry weight. The inter-

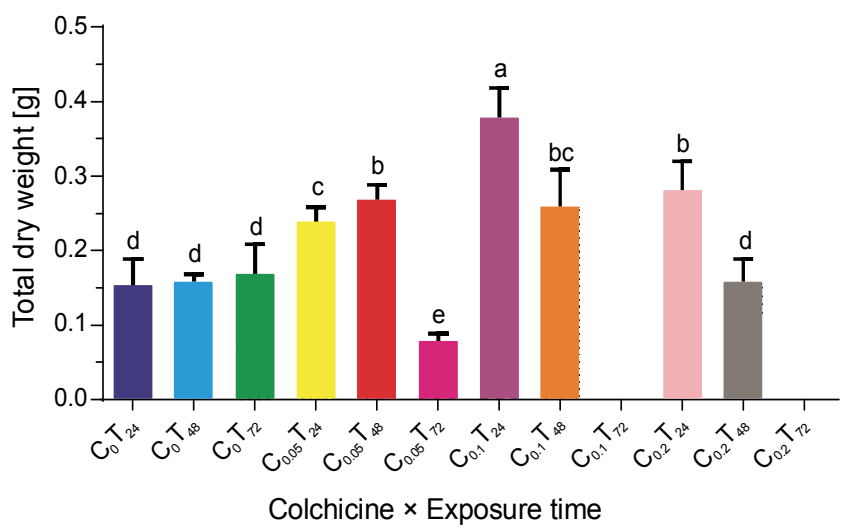

Fig. 1. A comparison of the effect of colchicine concentrations and exposure times on total dry weight; mean values \pm standard error of the mean (SEM) are derived from three independent replicates; the values superscripted by different letters are significantly different $(P \leq 0.01)$

action of $\mathrm{C} \times \mathrm{T}$ was significant in terms of total dry weight $(P \leq 0.01)$ (Table 1). The results showed that the total dry weight increased with the increase in the percentage of colchicine. The highest total dry weight $(0.38 \pm 0.04 \mathrm{~g})$ was observed at $0.1 \%$ colchicine and $24 \mathrm{~h}$ exposure time, while the treatment of plants with $0.05 \%$ colchicine and $72 \mathrm{~h}$ exposure time resulted in a slight decrease in the total dry weight $(0.08 \pm 0.01 \mathrm{~g})$ in comparison to controls $(0.13 \pm 0.04 \mathrm{~g})$ - Figure 1 . The plants indicated stress symptoms such as leaf fall due to a high concentration of colchicine. The symptoms and lethality also increased with the increase in the colchicine concentration and exposure time The symptoms and lethality varied depending on the concentration of colchicine and exposure time, for example, the total shoot and root dry weight of plants treated with $0.05 \%$ colchicine for $72 \mathrm{~h}$ was $0.08 \pm 0.01 \mathrm{~g}$, whereas the plants treated with 0.1 and $0.2 \%$ colchicine for $72 \mathrm{~h}$ were unable to survive.

\section{Effect of colchicine concentrations and exposure times} on chlorophyll and carotenoid contents

The results indicated that colchicine concentrations (C) and exposure times ( $\mathrm{T}$ ) significantly affected chlorophyll a, chlorophyll b, and carotenoid contents. The interaction of $\mathrm{C} \times \mathrm{T}$ was significant in terms of chlorophyll a, chlorophyll b, and carotenoid contents $(P \leq 0.01)$ (Table 1). The results revealed that chlorophyll a, chlorophyll $\mathrm{b}$, and carotenoid contents increased with the increase in the percentage of colchicine up to $1 \%$, while chlorophyll a, chlorophyll b, and carotenoid contents decreased with the increase in the exposure time of col- 
Table 1. A variance analysis of the effect of colchicine concentrations and exposure times on some physiological traits of Melissa officinalis

\begin{tabular}{|c|c|c|c|c|c|c|c|c|c|c|c|}
\hline \multirow{2}{*}{ S.O.V } & \multirow{2}{*}{ df } & \multicolumn{10}{|c|}{ Mean square } \\
\hline & & TDW & Chl. $a$ & Chl. $b$ & Caro & Phenol & Flavo & RMA & NS & $\mathrm{SL}$ & SW \\
\hline Colchicine (C) & 3 & $0.017^{*}$ & $7.77^{* *}$ & $0.68^{* *}$ & $51888.2^{* *}$ & $2625.8^{*}$ & $1889.1^{* *}$ & $0.11^{* *}$ & $124.36^{* *}$ & $0.018^{* *}$ & $0.008^{* *}$ \\
\hline Time $(\mathrm{T})$ & 2 & $0.024^{\text {** }}$ & $2.18^{*}$ & $0.15^{* *}$ & $4731.7^{* *}$ & $3860.9^{*}$ & $613.6^{*}$ & $0.23^{* *}$ & $3.72^{\mathrm{ns}}$ & $0.007^{\mathrm{ns}}$ & $0.003^{\mathrm{ns}}$ \\
\hline $\mathrm{C} \times \mathrm{T}$ & 6 & $0.040^{\text {** }}$ & $0.56^{* *}$ & $0.60^{* *}$ & $1758.0^{*}$ & $2446.1^{\mathrm{ns}}$ & $717.4^{*}$ & $0.01^{* * *}$ & $4.54^{\mathrm{ns}}$ & $0.01^{\mathrm{ns}}$ & $0.005^{\mathrm{ns}}$ \\
\hline Error & 18 & 0.004 & 0.03 & 0.01 & 615.2 & 1030.8 & 227.4 & 0.00 & 6.76 & 0.01 & 0.00 \\
\hline
\end{tabular}

TDW - total dry weight, Chlo. $a$ - chlorophyll $a$, Chlo. $b$ - chlorophyll $b$, Caro - carotenoid, Flavo - flavonoid, RMA - rosmarinic acid, NS - number of stomata, SL - stomatal length, SW - stomatal width

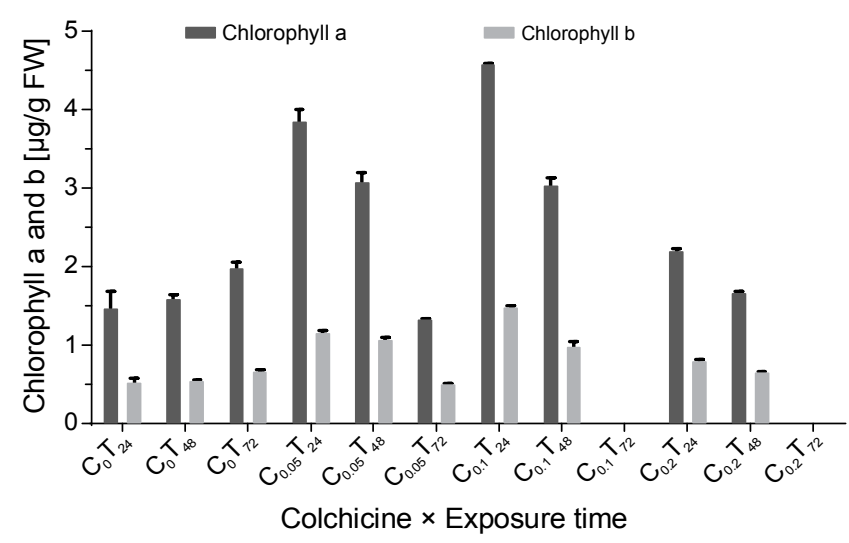

Fig. 2. Mean comparison of the effect of colchicine concentrations and exposure times on chlorophyll a and chlorophyll $b$ contents; mean values \pm standard error of the mean (SEM) are derived from three independent replicates $(P \leq 0.01)$

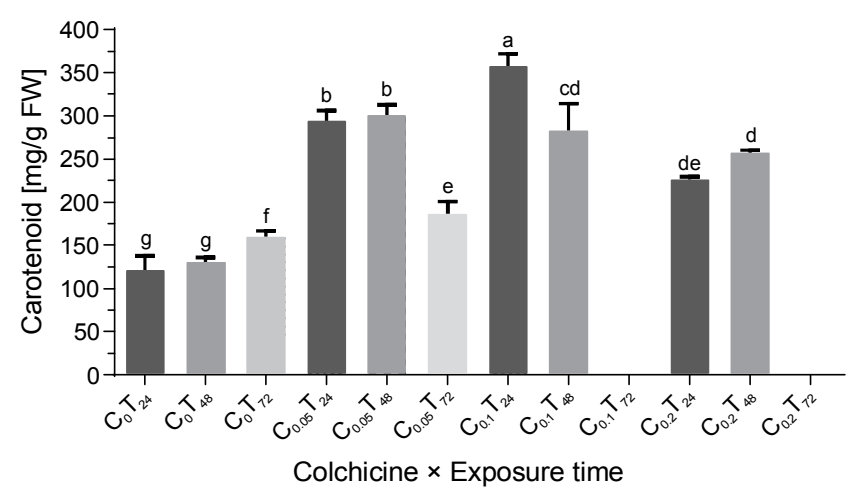

Fig. 3. Mean comparison of the effect of colchicine concentrations and exposure times on carotenoid contents; mean values \pm standard error of the mean (SEM) are derived from three independent replicates; the values superscripted by different letters are significantly different $(P \leq 0.01)$

chicine. The highest chlorophyll a $(4.60 \pm 0.01 \mu \mathrm{g} / \mathrm{g} \mathrm{FW})$, chlorophyll b $(1.49 \pm 0.03 \mu \mathrm{g} / \mathrm{g} \mathrm{FW})$, and carotenoid contents $(357.2 \pm 14.7 \mu \mathrm{g} / \mathrm{g} \mathrm{FW})$ were observed at $0.1 \%$ col- chicine and $24 \mathrm{~h}$ exposure time compared to the control for chlorophyll a $(1.49 \pm 0.2 \mu \mathrm{g} / \mathrm{g} \mathrm{FW})$, chlorophyll b $(0.52 \pm 0.07 \mu \mathrm{g} / \mathrm{g} \mathrm{FW})$, and carotenoid contents (121.3 $\pm 16.2 \mu \mathrm{g} / \mathrm{g} \mathrm{FW}$ ) (Fig. 2 and Fig. 3). The treatment of plants with $0.05 \%$ colchicine and $72 \mathrm{~h}$ exposure time resulted in a slight decrease in chlorophyll a, chlorophyll b, and carotenoid contents compared to $0.1 \%$ treatment and $24 \mathrm{~h}$ exposure time. The plants indicated stress symptoms and lethality depending on colchicine concentration and exposure time. The mortality rate at $0.1 \%$ and $0.2 \%$ colchicine for $72 \mathrm{~h}$ was $100 \%$.

\section{Effect of colchicine concentrations and exposure times on the total phenolic content}

The results of the analysis of variance indicated that the main effect of colchicine and exposure time significantly affected the total phenolic content $(P \leq 0.05)$, while the interaction of colchicine and exposure time had no significant influence on the total phenolic content (Table 1). The results showed that the highest total phenolic content $(62.88 \pm 5.6 \mu \mathrm{g} / \mathrm{g} \mathrm{FW})$ was obtained at $0.05 \%$ colchicine in comparison to the control plant $(15.70 \pm 0.47 \mu \mathrm{g} / \mathrm{g} \mathrm{FW})$, while the increase in the exposure time led to a decrease in the total phenolic content (Fig. 4).

\section{Effect of colchicine concentrations and exposure times on the total flavonoid content}

Colchicine concentrations $(\mathrm{C})$ and exposure times $(\mathrm{T})$ significantly affected the total flavonoid content. The interaction of $\mathrm{C} \times \mathrm{T}$ was significant in terms of the total flavonoid content $(P \leq 0.01)$ - Table 1 . The results revealed that the total flavonoid content increased with the increase in the colchicine concentration of up to $0.1 \%$. The highest total flavonoid content $(64.7 \pm 19.4 \mathrm{mg} / \mathrm{g})$ 

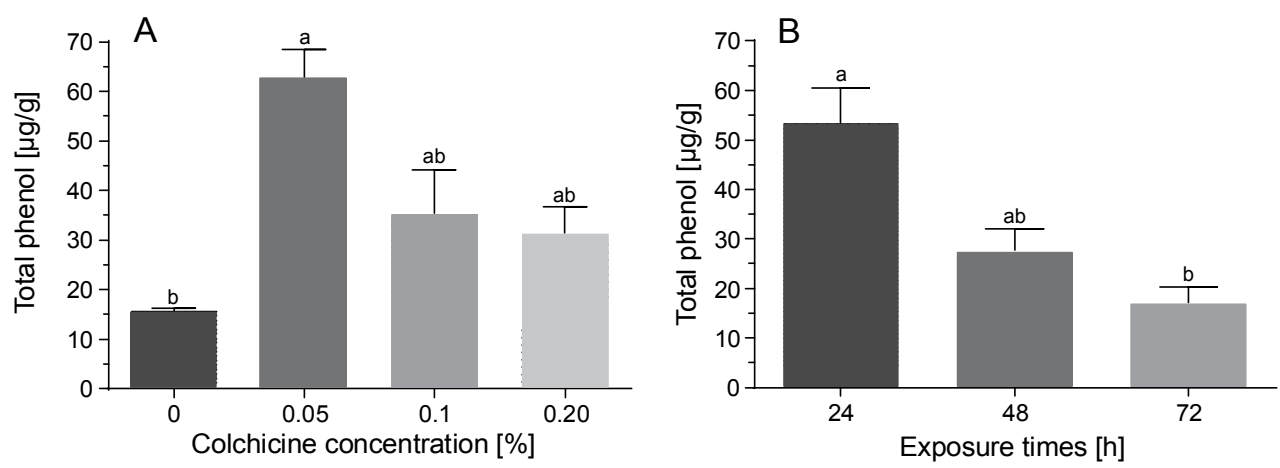

Fig. 4. Mean comparison of A) different colchicine concentrations and B) exposure times on the total phenol content; mean values \pm standard error of the mean (SEM) are derived from three independent replicates; the values superscripted by different letters are significantly different

$(P \leq 0.01)$

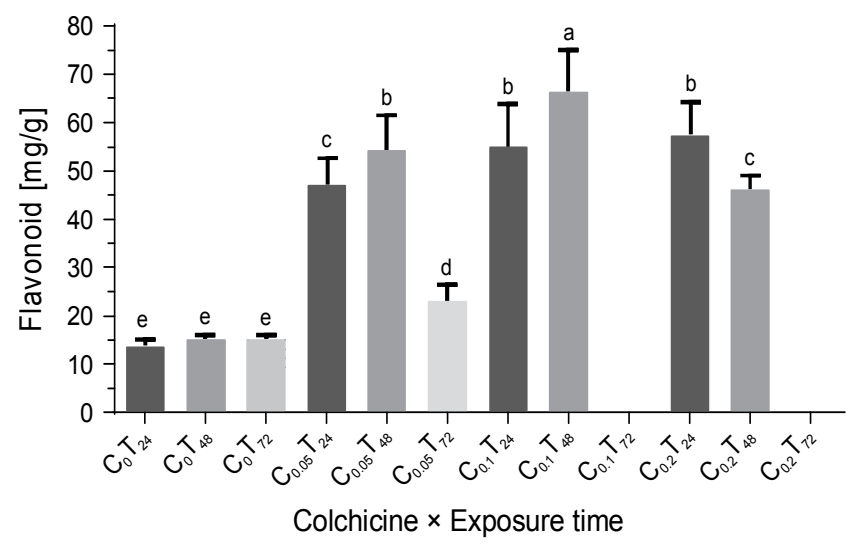

Fig. 5. Comparison of colchicine concentrations and exposure times on the total flavonoid content; mean values \pm standard error of the mean (SEM) are derived from three independent replicates; the values superscripted by different letters are significantly different $(P \leq 0.01)$

was observed at $0.1 \%$ colchicine and $48 \mathrm{~h}$ exposure time, while the treatment of plants with $0.05 \%$ colchicine and $24 \mathrm{~h}$ exposure time resulted in a slight decrease in the total flavonoid content compared to the total flavonoid content of $13.1 \pm 1.3 \mu \mathrm{g} / \mathrm{g} \mathrm{FW}$ in the control plant (Fig. 5).

\section{Effect of colchicine concentrations and exposure times on the rosmarinic acid content}

The HPLC results indicated that the highest rosmarinic acid content $(0.98 \pm 0.01 \mathrm{mg} / \mathrm{g} \mathrm{DW})$ was observed at $0.05 \%$ colchicine concentration and $48 \mathrm{~h}$ exposure time, while the treatment of plants with $0.2 \%$ colchicine and $24 \mathrm{~h}$ exposure time resulted in a slight decrease in the rosmarinic acid content compared to the rosmarinic acid content of $0.64 \pm 0.01 \mathrm{mg} / \mathrm{g} \mathrm{DW}$ in the controls (Fig. 6).

\section{Effect of colchicine concentrations and exposure times on the size and density of stomata}

The analysis of variance showed that the colchicine concentration affected significantly the size and density of stomata, while exposure times and the interaction of $\mathrm{C} \times \mathrm{T}$ were not significant in terms of the size and density of the stomata of lemon balm (Table 1). Among colchicine concentrations, $0.2 \%$ colchicine yielded the lowest density of stoma $(6.19 \pm 0.43)$, followed by $0.1 \%$ and $0.05 \%$ concentrations and the controls $(0 \%)$. The results showed that the size of the stomata in colchicinetreated plants was larger than that in diploid plants. The length of stomata varied depending on different colchicine concentrations, ranging from $31.19 \pm 0.59 \mu \mathrm{m}$ (controls) to $39.93 \pm 0.75 \mu \mathrm{m}(0.2 \%$ colchicine $)$, and their width varied from $17.94 \pm 0.47 \mu \mathrm{m}$ (controls) to 23.20 $\pm 0.71 \mu \mathrm{m}$ ( $0.2 \%$ colchicine) (Fig. 7 and Fig. 8 ).

\section{Determination of the ploidy levels of plants by flow cytometry}

The 2-month-old controls and tetraploid plants were analyzed by flow cytometry for chromosome number confirmation. The results of the flow cytometric analysis indicated that the fluorescence intensity peak position in a diploid sample $(2 \times)$ was almost 160 (Fig. 9A), while the peak of the tetraploid sample $(4 \times)$ was 320 (Fig. 9B). The result of flow cytometry showed that tetraploidy was detected in plants derived from the germinating seeds exposed to $0.2 \%$ colchicine for $24 \mathrm{~h}$. No tetraploidy was detected in seedlings exposed to other colchicine concentrations. This result suggests that $0.2 \%$ colchicine treatment for $24 \mathrm{~h}$ was sufficient to induce cell polyploidization, whereas $0.2 \%$ colchicine for $48 \mathrm{~h}$ treatment had some toxic effects such as leaf fall. 


\section{A}
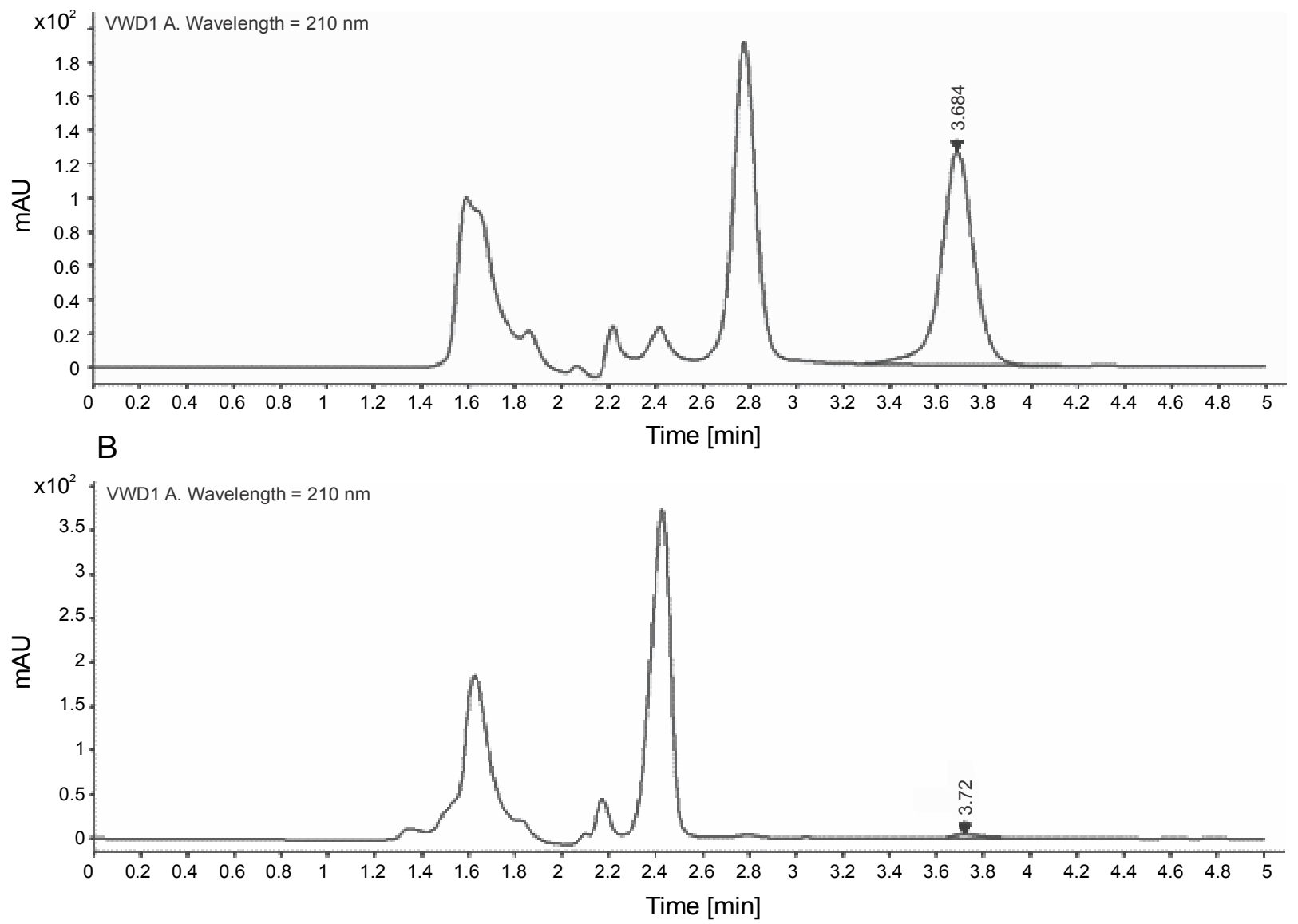

Fig. 6. HPLC chromatogram of lemon balm treated with A) $0.05 \%$ colchicine and $48 \mathrm{~h}$ exposure time and B) $0.2 \%$ colchicine and $24 \mathrm{~h}$ exposure time
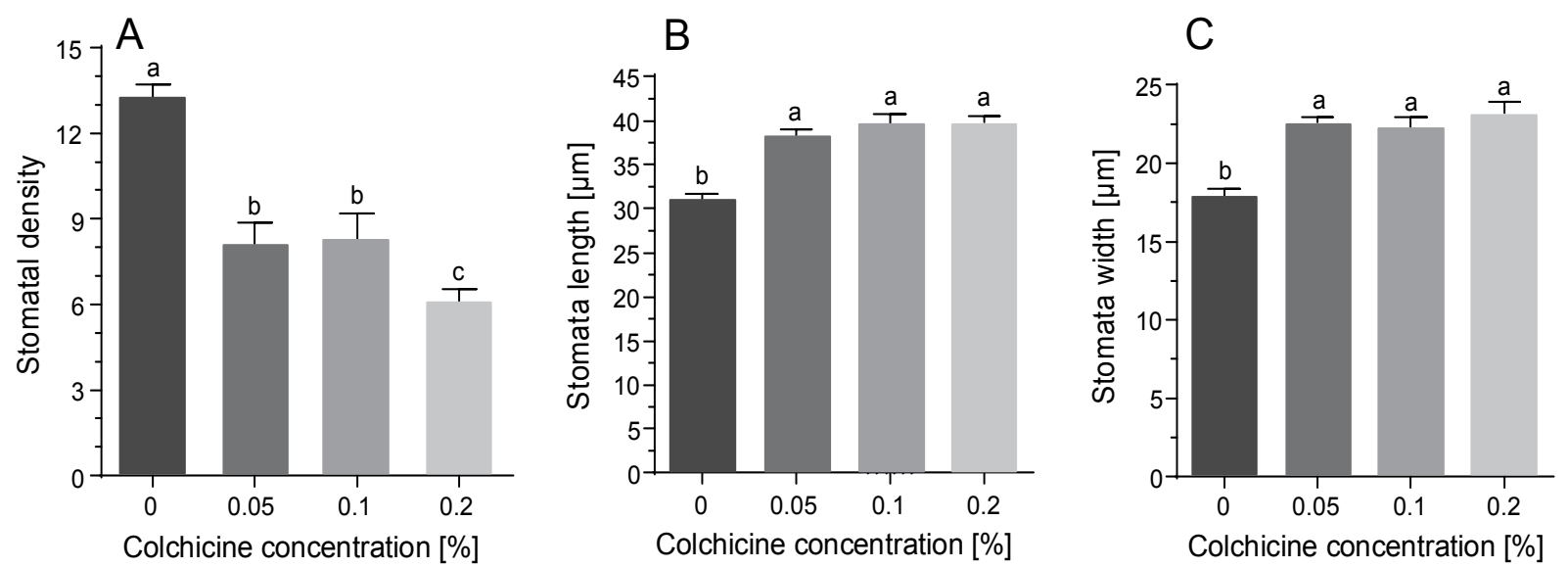

Fig. 7. Mean comparison of colchicine concentrations on A) the density, B) length, and C) width of stomata in lemon balm; mean values \pm standard error of the mean (SEM) are derived from three independent replicates; the values superscripted by different letters are significantly different $(P \leq 0.01)$

To confirm the flow cytometry results, the chromosome number of each sample was counted using a microscope at $40 \times$ magnification (Olympus BX40). Cells from tetraploid plants had $2 n=4 x=44$ chromosomes, which was twice the number of chromosomes in the diploid controls $(2 n=2 x=22)$ (Fig. 10). This indicated that flow cytometry can be used for the identification of polyploidy in lemon balm. 


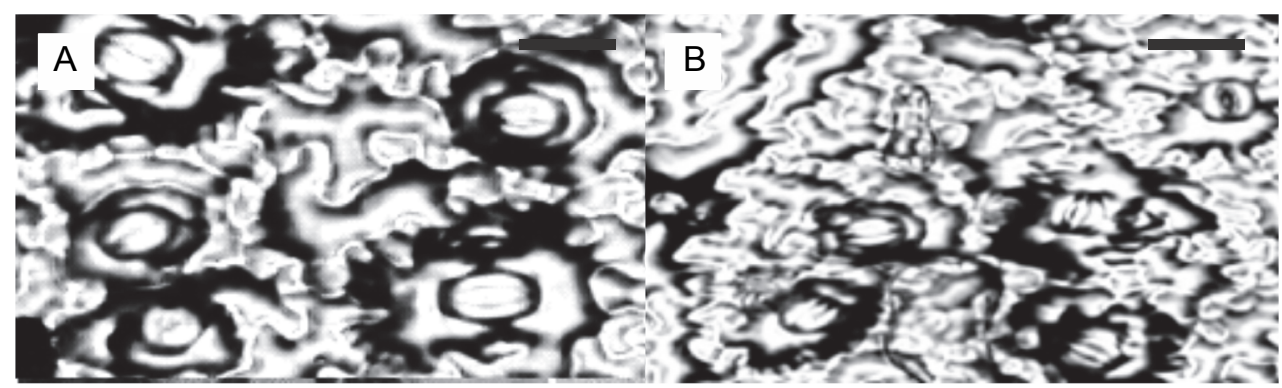

Fig. 8. The size of the stoma of A) a colchicine-treated and B) untreated plant; stomata were obtained from the same parts of the leaves in the control and treated plants and observed under a light microscope at $40 \times$ and $100 \times$ magnification $($ scale bar $=40 \mu \mathrm{m}$ )
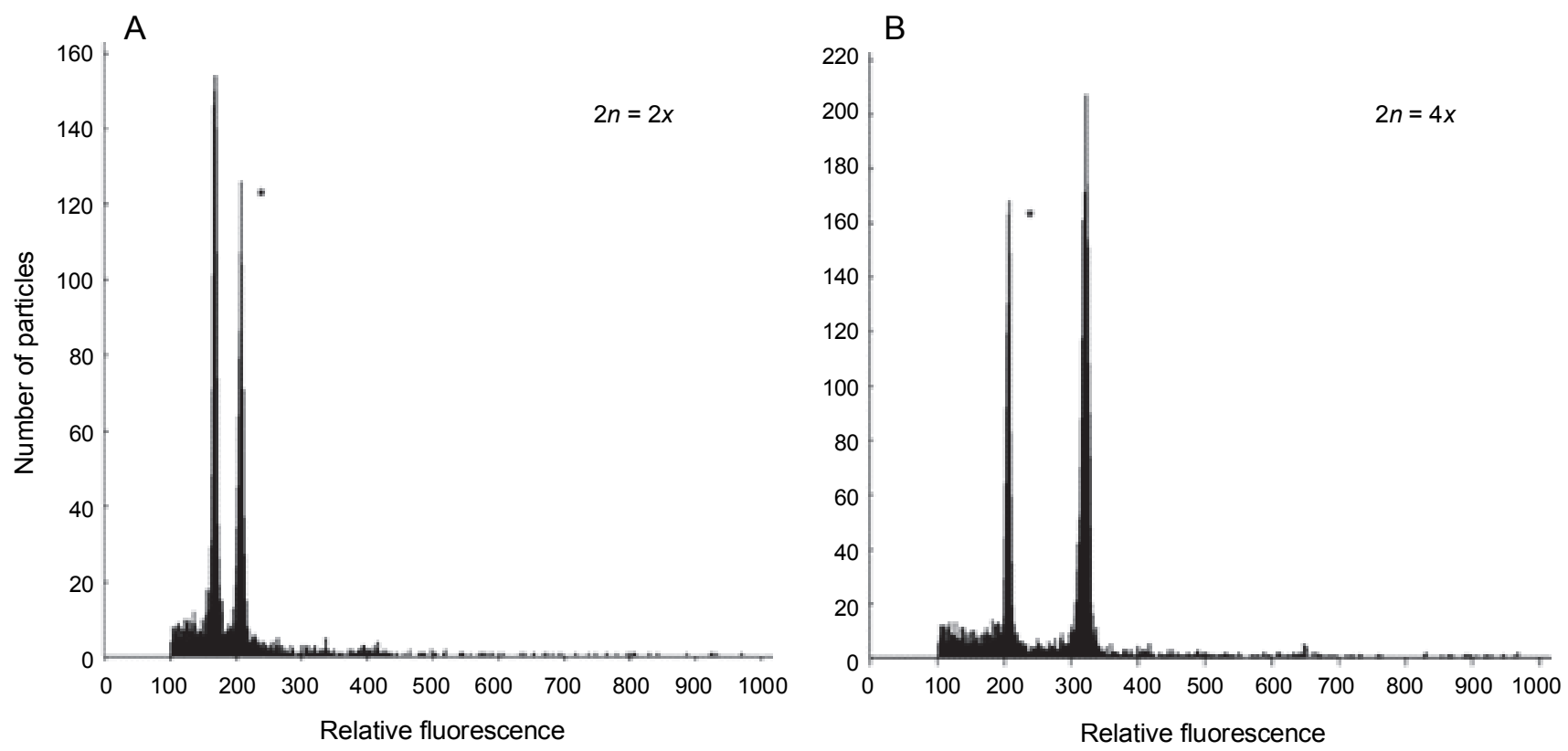

Fig. 9. Histogram of the flow cytometric analysis of Melissa officinalis L. A) diploid $(2 n=2 x=32)$ and B) tetraploid plant $(2 n=4 x=64)$

\section{Discussion}

Improvement of plant characteristics is required for an effective development of new varieties that are of high pharmaceutical and economical interest. Polyploidy is an interesting phenomenon in plants and plays a major role in plant evolution by establishing an important pathway for diversification and genetic variations (Bennett, 2004). In our study, the highest rate of chromosome doubling was achieved when the explants were treated with $0.2 \%$ colchicine for $24 \mathrm{~h}$, which was associated with the highest plant survival rates without toxic effects, while a longer duration of treatment $(72 \mathrm{~h})$ at $0.1 \%$ and $0.2 \%$ colchicine concentrations was found to be lethal.
The application of colchicine was found to be effective for chromosome doubling of many crops, including feverfew (Tanacetum parthenium L.) (Saharkhiz, 2007), Acacia mangium (Harbard et al., 2012), Swamp rose mallow (Hibiscus moscheutos) (Li and Ruter, 2017), White orchid tree (Bauhinia acuminata) (Basumatari and Das, 2017), Sultana (Impatiens walleriana) (Wang et al., 2018), and Gladiolus (Gladiolus grandiflorus) (Manzoor et al., 2018).

The size and density of stomata have been used to differentiate between colchicine-treated and untreated plants (Omezzine et al., 2012; Vanitha et al., 2013). As seen in stomatal size, plants under $0.2 \%$ colchicine treat- 


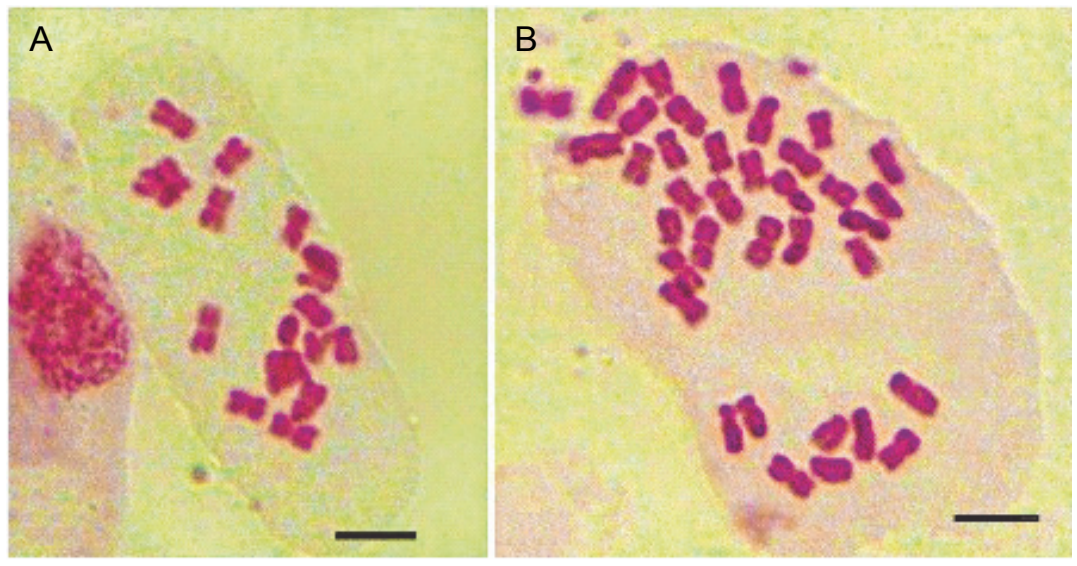

Fig. 10. The chromosomes of A) diploid $(2 n=2 x=32)$ and B) tetraploid $(2 n=4 x=64)$ plants of Melissa officinalis L.

ment showed a higher ploidy level than the untreated plants. The stomatal size increased in the tetraploid plants, but the stomatal density decreased (Fig. 7). These observations are in agreement with the results of Chen and Gao (2007) on Astragalus membranaceus, Tang et al. (2010) on Paulownia tomentosa, Wannakrairoj and Tefera (2013) on Aframomum corrorima, and Ghani et al. (2014) on Mentha mozaffarianii; these authors reported that the mean length of the stomata was higher in tetraploid plants than in diploid plants. However, the stomatal number per unit was significantly reduced by increasing the ploidy level due to the increased stomatal size. High ploidy levels resulting in lower stomatal density have previously been confirmed in M. mozaffarianii (Ghani et al., 2014), and Tagetes erecta (Sajjad et al., 2013).

The present study showed that tetraploids had a higher chlorophyll index as well as higher fresh and dry weights than diploids. Similar results were previously reported in feverfew (Saharkhiz, 2007), M. mozaffarianii (Ghani et al., 2014), strawberry (Murti et al., 2012), and Echinacea purpurea (Abdoli et al., 2013). In the present study, tetraploids showed higher fresh and dry weights than diploids, whereas the dry weight of Vicia villosa (Tulay and Unal, 2010) and Anthurium andraeanum (Chen et al., 2011) was higher in diploids than in tetraploids. Our results also agreed well with the findings of Maruska et al. (2010) who showed that polyploidy allows to develop plant forms containing higher amounts of biologically active compounds than their initial diploid forms.
In agreement with the reports of Manzoor et al. (2018) on gladiolus ( $G$. grandiflorus), Wang et al. (2018) on Sultana (I. walleriana), and Li and Ruter (2017) on Swamp rose mallow (Hibiscus moscheutos), the findings of the present study indicated that a low concentration of colchicine facilitated plant growth as indicated by an increase in certain measured morphological and phytochemical traits such as total dry weight and phenol, flavonoid, and rosmarinic acid contents. Various studies have reported that under an extremely high concentration of colchicine, the plant growth was inhibited and the mortality rate of plants increased due to toxic effects (Maruska et al., 2010; Sajjad et al., 2013; Talebi et al., 2017). Apparent variations in cytological and morphological traits compared to the diploid plants were observed for the tetraploid lemon balm plants analyzed in the present study (Fig. 9 and Fig. 10). The tetraploid plants had significantly larger stomata and higher rosmarinic acid contents, suggesting that the tetraploid plants may have higher photosynthetic and transpiration capacities. The remarkable differences in morphological phenotypes, stomata size, and density in the tetraploid plants may explain their elevated levels of rosmarinic acid content, because lemon balm leaves are the main tissue for both synthesis and primary accumulation of rosmarinic acid (Yadav et al., 2011). Our results indicated that the levels of rosmarinic acid content were higher in tetraploid plants than in diploid plants. In this study, tetraploid lemon balm plants had improved characteristics, including growth indices, stomata size and rosmarinic acid content. 
In the present study, the analysis of chromosome number and the flow cytometric analysis demonstrated the induction of tetraploid individuals $(2 n=4 x=64)$ from diploid plants after the treatment of $M$. officinalis L. with colchicine. Moghbel et al. (2015) showed that the DNA content increased because of polyploidy induction in safflower and licorice plants. The basic method used for ploidy estimation is a flow cytometric analysis, which is a quick, reliable, and widely used technique for identifying ploidy in plants (Urwin et al., 2007). The flow cytometric analysis reduces the time needed to determine the ploidy level in safflower and licorice plants (Moghbel et al., 2015), and its reliability has been proven in cytological analyses (Harbard et al., 2012; Pereira et al., 2014; Talebi et al., 2017).

\section{Conclusions}

Increasing the concentration of colchicine decreased the survival rate of $M$. officinalis $\mathrm{L}$. The explants treated with $0.2 \%$ colchicine for $24 \mathrm{~h}$ showed the maximum rate of polyploid induction. By increasing the ploidy level, the stomatal features as well as the morpho-physiological characteristics of the plant markedly changed. Moreover, the techniques of polyploid induction could be considered as models for polyploidy manipulation in other medicinal and ornamental plants.

\section{References}

Abdoli M., Moieni A., Badi H.N. (2013) Morphological, physiological, cytological and phytochemical studies in diploid and colchicine-induced tetraploid plants of Echinacea purpurea (L.). Acta Physiol. Plant. 35: 2075-2083.

Alam H., Razaq M. (2015) Induced polyploidy as a tool for increasing tea (Camellia sinensis L.) production. J. North. Agric. Univ. (English Edition) 22: 43-47.

Alam M. (2011) Induction and evaluation of polyploidy in some local potato varieties of Bangladesh. J. Biodivers. Environ. Sci. (JBES) 1: 6-21.

Amiri S., Kazemitabaar S., Ranjbar G., Azadbakht M. (2010) The effect of trifluralin and colchicine treatments on morphological characteristics of jimsonweed (Datura Stramonium L.). Trakia J. Sci. 8: 47-61.

Bagdat R.B., Cosge B. (2012) The essential oil of lemon balm (Melissa officinalis L.), its components and using fields. Anadolu J. Agric. Sci. 21: 116-121.

Basumatari M., Das B.N. (2017) Karyomorphological studies in two species of Bauhinia Linn. and induction of polyploidy in Bauhinia acuminata Linn. Int. J. Life Sci. Sci. Res 3: $1223-1229$.
Bennett M.D. (2004) Perspectives on polyploidy in plants - ancient and neo. Biol. J. Linnean Soc. 82: 411-423.

Castro C.M., de Oliveira A., de Carvalho F. (2003) Changes in allele frequencies in colchicine-treated ryegrass populations assessed with RAPD markers. Rev. Brasil. Agrocien. (Brazil). 9: 107-112.

Chavan R., Mahadi S., Ashok T., Shashidhar H., Vasundhara M. (2014) Induction of genetic variability in Stevia rebaudiana Bertoni. Eco. Env. Cons. 20: 1273-1281.

Chen C., Hou X., Zhang H., Wang G., Tian L. (2011) Induction of Anthurium andraeanum "Arizona" tetraploid by colchicine in vitro. Euphytica 181: 137-145.

Chen L.L., Gao S.L. (2007) In vitro tetraploid induction and generation of tetraploids from mixoploids in Astragalus membranaceus. Sci. Horti. 112: 339-344.

Dhamayanthi K., Gotmare V. (2010) Induction of polyploidy in two diploid wild cotton (G. armourianum and G. aridum) species by colchicine treatment. Electron. J. Plant Breed 1: 966-972.

Dhawan O., Lavania U. (1996) Enhancing the productivity of secondary metabolites via induced polyploidy: a review. Euphytica 87: 81-89.

Dhooghe E., Van Laere K., Eeckhaut T., Leus L., Van Huylenbroeck J. (2011) Mitotic chromosome doubling of plant tissues in vitro. Plant Cell Tiss. Organ. Cult. (PCTOC) 104: 359-373.

Escandon A.S., Miyajima I., Alderete M., Hagiwara J.C., Facciuto G., Mata D., Soto S.M. (2005) Wild ornamental germplasm exploration and domestication based on biotechnological approaches: in vitro colchicine treatment to obtain a new cultivar of Scoparia montevidiensis. Electron. J. Biotech. 8: 86-93.

Ghani A., Neamati S.H., Azizi M., Saharkhiz M.J., Farsi M. (2014) Artificial autotetraploidy induction possibility of two Iranian endemic mint (Mentha mozaffarianii) ecotypes. Notulae Sci. Biol. 6: 185-191.

Hamill S., Smith M., Dodd W. (1992) In vitro induction of banana autotetraploids by colchicine treatment of micropropagated diploids. Austral. J. Bot. 40: 887-896.

Harbard J., Griffin A., Foster S., Brooker C., Kha L., Koutoulis A. (2012) Production of colchicine-induced autotetraploids as a basis for sterility breeding in Acacia mangium Willd. Forestry: Inter. J. Forest Res. 85: 427-436.

Kim S., Yun E.J., Bak J.S., Lee H., Lee S.J., Kim C.T., Lee J.H., Kim K.H. (2010) Response surface optimised extraction and chromatographic purification of rosmarinic acid from Melissa officinalis leaves. Food Chem. 121:521-526.

Kittler J., Schrader O., Kästner U., Marthe F. (2015) Chromosome number and ploidy level of balm (Melissa officinalis). Mol. Cytogen. 8: 61.

Li Z., Ruter J.M. (2017) Development and evaluation of diploid and polyploid Hibiscus moscheutos. HortSci. 52: 676-681.

Lichtenthaler H.K. (1987) Chlorophylls and carotenoids: pigments of photosynthetic biomembranes. Meth. Enzymol. 148: 350-382. 
Manzoor A., Ahmad T., Bashir M.A., Baig M.M.Q., Quresh A.A., Shah M.K.N., Hafiz I.A. (2018) Induction and identification of colchicine induced polyploidy in Gladiolus grandiflorus 'White Prosperity'. Folia Horticult. 30: 307-319.

Manzoor A., Ahmad T., Bashir M.A., Hafiz I.A., Silvestri C. (2019) Studies on colchicine induced chromosome doub ling for enhancement of quality traits in ornamental plants. Plants 8: 194.

Marinova D., Ribarova F., Atanassova M. (2005) Total phenolics and total flavonoids in Bulgarian fruits and vegetables. J. Univ. Chem. Tech. Metal. 40: 255-260.

Maruska A., Proscevicius J., Bimbiraite-Surviliene K., Kornysova O., Ragazinskiene O., Ratautaite V. (2010) Comparison of phytochemical composition of medicinal plants by means of chromatographic and related techniques. Proc. Chem. 2: 83-91.

Mishra B., Pathak S., Sharma A., Trivedi P., Shukla S. (2010) Modulated gene expression in newly synthesized autotetraploid of Papaver somniferum L. South Afr. J. Bot. 76: 447-452.

Moghbel N., Borujeni M.K., Bernard F. (2015) Colchicine effect on the DNA content and stomata size of Glycyrrhiza glabra var. glandulifera and Carthamus tinctorius L. cultured in vitro. J. Gen. Eng. Biotech. 13: 1-6.

Munzbergova Z. (2017) Colchicine application significantly affects plant performance in the second generation of synthetic polyploids and its effects vary between populations. Ann. Bot. 120: 329-339.

Murashige T., Skoog F. (1962) A revised medium for rapid growth and bio assays with tobacco tissue cultures. Physiol. Plant. 15: 473-497.

Murti R.H., Kim H.Y., Yeoung Y.R. (2012) Morphological and anatomical characters of ploidy mutants of strawberry. Int. J. Agric. Biol. 14: 204-210.

Ojiewo C.O., Murakami K., Masinde P.W., Agong S.G. (2007) Polyploidy breeding of African nightshade (Solanum section Solanum). Int. J. Plant Breed. 1: 10-21.

Omezzine F., Ladhari A., Nefzi F., Harrath R., Aouni M., Haouala R. (2012) Induction and flow cytometry identification of mixoploidy through colchicine treatment of Trigonella foenum-graecum L. Afr. J. Biotech. 11: 16434-16442.

Otto S.P. (2007) The evolutionary consequences of polyploidy. Cell 131: 452-462.

Ozturk M., Duru M.E., Ince B., Harmandar M., Topcu G. (2010) A new rapid spectrophotometric method to determine the rosmarinic acid level in plant extracts. Food Chem. 123: 1352-1356.

Pereira R.C., Ferreira M.T.M., Davide L.C., Pasqual M., Mittelmann A., Techio V.H. (2014) Chromosome duplication in Lolium multiflorum Lam. Crop Breed. Appl. Biotech. 14: 251-255.

Petersen K.K., Hagberg P., Kristiansen K. (2003) Colchicine and oryzalin mediated chromosome doubling in different genotypes of Miscanthus sinensis. Plant Cell Tissue Organ Cult. 73: 137-146.
Saharkhiz M. (2007) The effects of some environmental factors and ploidy level on morphological and physiological characteristics of feverfew (Tanacetum parthenium L.) medicinal ornamental plant. Iran. Dissertation, Tarbiat Modares University: 173.

Sajjad Y., Jaskani M.J., Mehmood A., Ahmad I., Abbas H. (2013) Effect of colchicine on in vitro polyploidy induction in African marigold (Tagetes erecta). Pak. J. Bot 45: 1255-1258.

Sakhanokho H.F., Rajasekaran K., Kelley R.Y., Islam-Faridi N. (2009) Induced polyploidy in diploid ornamental ginger (Hedychium muluense RM Smith) using colchicine and oryzalin. HortSci. 44: 1809-1814.

Soltani Maivan E., Radjabian T., Abrishamchi P., Talei, D., (2017) Physiological and biochemical responses of Melissa officinalis $L$. to nickel stress and the protective role of salicylic acid. Arch. Agron. Soil Sci. 63: 330-343.

Stanys V., Staniene G., Iikßnianas T. (2004) In vitro induction of polyploidy in In vitro Ribes. Acta Univ. Latv. 676: 235-676.

Talebi S.F., Saharkhiz M.J., Kermani M.J., Sharafi Y., Raouf Fard F. (2017) Effect of different antimitotic agents on polyploid induction of anise hyssop (Agastache foeniculum L.). Caryologia 70: 184-193.

Tang Z.-Q., Chen D.-L., Song Z.-J., He Y.-C., Cai D.-T. (2010) In vitro induction and identification of tetraploid plants of Paulownia tomentosa. Plant Cell Tissue Organ Cult. (PCTOC) 102: 213-220.

Thao N.T.P., Ureshino K., Miyajima I., Ozaki Y., Okubo H. (2003) Induction of tetraploids in ornamental Alocasia through colchicine and oryzalin treatments. Plant Cell Tissue Organ Cult. 72: 19-25.

Tulay E., Unal M. (2010) Production of colchicine induced tetraploids in Vicia villosa roth. Caryologia 63: 292-303.

Urwin N.A., Horsnell J., Moon T. (2007) Generation and characterisation of colchicine-induced autotetraploid Lavandula angustifolia. Euphytica 156: 257-266.

Vainola A. (2000) Polyploidization and early screening of Rhododendron hybrids. Euphytica 112: 239-244.

Vanitha J., Jiang S., Ramachandran S. (2013) Impact of Colchicine Treatment on Sorghum bicolor BTÃ-623. Mol. Plant Breed. 4: 128-135.

Vijaykumar K., Murthy P.B., Kannababu S., Syamasundar B., Subbaraju G.V. (2007) Estimation of Adrographolide in Andrographis paniculata herb, extracts and dosage forms. Int. J. Appl. Sci. Eng. 5: 27-39.

Wang W., He Y., Cao Z., Deng Z. (2018) Induction of tetraploids in impatiens (Impatiens walleriana) and characterization of their changes in morphology and resistance to downy mildew. HortSci. 53: 925-931.

Wannakrairoj S., Tefera W. (2013) In vitro chromosome doubling in Korarima [Aframomum corrorima (Braun) PCM Jansen] using colchicine and oryzalin. Kasetsart J. Nat. Sci. 47: 684-694. 
Weitzel C., Petersen M. (2011) Cloning and characterisation of rosmarinic acid synthase from Melissa officinalis $L$. Phytochemistry 72: 572-578.

Yadav A.K., Singh S., Dhyani D., Ahuja P.S. (2011) A review on the improvement of stevia [Stevia rebaudiana (Bertoni)]. Canad. J. Plant Sci. 91: 1-27.
Yokoya K., Roberts A., Mottley J., Lewis R., Brandham P. (2000) Nuclear DNA amounts in roses. Ann. Bot. 85: $557-561$.

Zlesak D.C., Thill C.A., Anderson N.O. (2005) Trifluralinmediated polyploidization of Rosa chinensis minima (Sims) Voss seedlings. Euphytica 141: 281-290. 